\title{
ANÁLISE MERCADOLÓGICA DA CADEIA PRODUTIVA DO CIPÓ- PRETO (Philodendron melanorrhizum Reitz) NA ÁREA DE PROTEÇÃO AMBIENTAL DE GUARATUBA (PR)
}

\author{
Dalvo Ramires Balzon ${ }^{1}$, Anadalvo Juazeiro dos Santos ${ }^{2}$, Ricardo Berger ${ }^{2}$, Luciano de Almeida ${ }^{3}$, \\ Alexandre Muzy Bittencourt ${ }^{4}$ \\ ${ }^{1}$ Economista, Dr., Instituto Brasileiro de Pós-graduação e Extensão, IBPEX, SPEI, Curitiba, PR, Brasil - dalvo.rb@terra.com.br \\ ${ }^{2}$ Eng. Florestal, Dr., Depto. de Economia Rural e Extensão, UFPR, Curitiba, PR, Brasil - ajsantos@ufpr.br - berger@ufpr.br \\ ${ }^{3}$ Eng. Agrônomo, Dr., Depto. de Economia Rural e Extensão da UFPR, Curitiba, PR, Brasil - luciano@agrarias.ufpr.br \\ ${ }^{4}$ Eng. Florestal, M.Sc., Doutorando em Engenharia Florestal, UFPR, Curitiba, PR, Brasil - alexbitten@terra.com.br
}

Recebido para publicação: 01/10/2006 - Aceito para publicação: 09/11/2007

\begin{abstract}
Resumo
Este estudo teve por objetivo realizar a análise mercadológica, assim como verificar a contribuição do cipópreto na geração de trabalho e renda para as comunidades rurais tradicionais localizadas na região da Área de Proteção Ambiental - APA de Guaratuba. Para atingir tais objetivos, a metodologia utilizada constou de análise para definir os fluxogramas, as quantidades extraídas e comercializadas, custos de produção, preços, receitas, margens de lucro, de comercialização e markup. Os resultados da atividade extrativista do cipópreto apontam a realização de aporte de renda mensal média inferior ao salário mínimo vigente, e pequena margem de lucro, embora represente possibilidade única de efetiva geração de renda para as famílias extrativistas. As maiores margens de comercialização são apropriadas pelos agentes distribuidores e varejistas, enquanto o markup é apropriado geralmente pelos intermediários. A produção artesanal possui estrutura claramente monopsônica, o que representa total dependência do extrativista/artesão frente ao agente comprador, tanto em termos de quantum extraído, como de preços de comercialização. O conjunto destas atividades possui forte dependência do mercado para manter-se em funcionamento e o seu desenvolvimento sustentado passa pelo acesso a novos mercados.

Palavras-chave: Philodendron melanorrhizum; produtos florestais não-madeiráveis; área de proteção ambiental; produção extrativista; margem e markup de comercialização.
\end{abstract}

\begin{abstract}
Marketing analysis on the productive chain of Philodendron melanorrhizum (cipó-preto) the environmental protection area in the county of Guaratuba, Parana, Brazil. This study presents of the marketing on the Philodendron melanorrhizum (cipó-preto) contribution to generating employment and earned income to the rural forest communities of the Area of Environmental Protection (AEP) in the county of Guaratuba. This research had as objective to describe the productive chain of cipo-preto being analyzed; flowchart harvested and marketed amounts, production costs, price, cash inflow, profit margin, market margin, and mark-up were defined. Cipo-preto harvesting makes possible to the families gel realize monthly an income usually lower than the minimum wage, with small profits, nonetheless it represents a remarkable occasion for. Retailers and wholesalers appropriate the largest market margins, and middlemen usually appropriate mark-up. Craft industry, which is very significant, is structured on a single buyer, and for the artisan that represents a dependency in terms of amounts and prices. These activities depend on the market for keep producing and their sustainable development requires new market to open up.

Keywords: Philodendron melanorrhizum; nontimber forest products; area of environmental protection; harvesting, market margins; mark-up.
\end{abstract}

\section{INTRODUÇÃO}

O crescimento das preocupações com as questões ambientais, e em particular com o aquecimento do planeta, colocou a preservação das florestas como uma questão de interesse internacional, fornecendo novas idéias sobre a relação entre desenvolvimento econômico e meio ambiente. 
A proposta parte do pressuposto de que o objetivo do desenvolvimento econômico das florestas é a manutenção da mesma, de forma que a estrutura produtiva daí decorrente deva ser elaborada visando à lucratividade e competitividade nos mercados.

Os Produtos Florestais Não Madeiráveis (PFNM's) têm sido estudado numa perspectiva de alternativa e renda sustentável à medida que possibilita geração de renda e trabalho, aliados a conservação florestal. Algumas das primeiras pesquisas sobre PFNM's que se destacam incluem o relatório da Organização Internacional de Madeira Tropical (ITTO, 1988) e Panayotou; Ashton (1992), que apareceram quase que simultaneamente e salientaram as necessidades de manejo sobre os Produtos Florestais Não Madeiráveis.

Borges; Braz (1998) definem os PFNM's como "os que podem ser extraídos da floresta com possibilidade de manejo sustentado. Entre eles encontram-se óleos, resinas, bambus, plantas medicinais, frutas, cipó etc." Outra definição é apresentada pelo Instituto Brasileiro de Geografia e Estatística (IBGE), citado por Santos et al. (2005), em que os PFNM's ou "produtos extrativos" da floresta compreendem a borracha, gomas não elásticas, ceras, fibras, tanantes, cipó, oleaginosas, alimentícias, aromáticas e subprodutos da silvicultura.

As Áreas de Proteção Ambiental - APA constituem-se de medida importante na sustentabilidade da conservação florestal. Instituída pela Lei $\mathrm{n}^{\mathbf{0}}$ 6.902, são Unidades de Conservação que abrigam atividades econômicas e convivem com comunidades no seu interior e no seu entorno, respeitando o regime de propriedade privada, inclusive posses, e aliando preocupações socioambientais e convivência com espaços urbanizados. Nesse contexto as populações locais tradicionais que dependem diretamente dos recursos naturais para sobreviver devem ser orientadas sobre o uso permitido desses recursos.

No Paraná, a Área de Proteção Ambiental (APA) de Guaratuba foi criada através do Decreto Estadual 1.234 de 27 de março de 1992, com área de 199.586 hectares. Localizada no entorno em interface com o perímetro urbano de Guaratuba e Matinhos e com terrenos rurais com maior e menor densidade demográfica dos municípios de Morretes, ainda no litoral do Paraná, Tijucas do Sul e São José dos Pinhais; abriga populações tradicionais, que segundo Lima (1996) detêm o conhecimento dos ciclos biológicos, a utilização dos recursos naturais e hábitos alimentares. Essas famílias têm dependência da renda parcial ou total na extração de PFNM's.

Sonda (2002) afirma que são desses produtos que as populações tradicionais da APA de Guaratuba dependem para sobreviver, especialmente da confecção de cestarias por intermédio do cipópreto (Philodendron melanorrhizum Reitz). Segundo Mayo et al. (1997), o cipó-preto faz parte do gênero Heteropsis, que tem aproximadamente 13 espécies distribuídas nas florestas tropicais da América Latina. Possui vários usos, dentre os quais se destaca a construção de casas, mais precisamente no que diz respeito à substituição de pregos e à fabricação de produtos artesanais, como cestarias, móveis, brinquedos, balaios etc.

Desta forma, o presente trabalho teve por objetivo realizar a análise mercadológica da cadeia produtiva do cipó-preto para as comunidades rurais tradicionais da Área de Proteção Ambiental - APA de Guaratuba (PR), numa perspectiva de geração de trabalho e renda que assegure a conservação dos remanescentes florestais.

Entende-se por Cadeia Produtiva como sendo os encadeamentos entre as diversas fases por onde passa um produto, desde os fornecedores de insumos até o destino final da produção, buscando a satisfação do consumidor (HADDAD et al., 1999).

\section{MATERIAL E MÉTODOS}

O universo da pesquisa abrangeu a totalidade das famílias (73) que extraem o cipó-preto para utilização comercial e que residem em 11 comunidades situadas no interior da APA de Guaratuba (PR), região denominada de Unidade de Estudos Agropecuários de Guaratuba (UEAG).

Essa unidade foi subdividida em duas sub-unidades. Fazem parte da primeira sub-unidade as comunidades rurais localizadas na região Sul da baía de Guaratuba, denominada de "mais integrada ao mercado" e da segunda, as comunidades rurais localizadas no interior e ao norte da baía de Guaratuba, entorno da estrada Cubatão/Limeira, denominada de "menos integrada ao mercado".

A diferença entre as duas sub-unidades é que nas comunidades "mais integradas ao mercado", o acesso é fácil, próximo da sede do município, e as famílias utilizam o cipó-preto para tecer artesanatos (cestos), enquanto nas comunidades "menos integradas ao mercado", o acesso é difícil, longe da sede do 
município, e as famílias utilizam o cipó-preto para vender sem beneficiamento. Das comunidades "mais integradas ao mercado" foram entrevistadas 55 famílias e, das comunidades "menos integradas ao mercado", foram entrevistadas 18 famílias.

Os dados para essa pesquisa foram coletados por meio da aplicação de questionários estruturados junto a líderes das comunidades e chefes das famílias. Também foram consultados técnicos do Instituto Ambiental do Paraná (IAP), Prefeitura Municipal de Guaratuba (PR), Empresa de Assistência Técnica e Extensão Rural (EMATER) e Instituto Brasileiro de Geografia e Estatística (IBGE), a partir de reuniões.

A metodologia utilizada na pesquisa de campo constou da elaboração de um questionário estruturado visando à análise do processo de extração, beneficiamento e comercialização, a construção de um fluxograma com as diversas fases da cadeia produtiva, quantificando-a em receita, custos e valor de venda, intermediário, distribuidor, varejo, consumo e a margem e markup de comercialização. Utilizou-se também para a presente análise a revisão de literatura, coleta e uso de dados secundários, elaboração de diagramas de fluxos e consultas a atores representativos da cadeia. As quantidades e preços representam as médias do ano de 2005. A obtenção destes dados para anos anteriores foi dificultada, face ao baixo nível de formação das pessoas entrevistadas.

As entrevistas ocorreram em duas etapas, assim distribuídas: a primeira realizou-se entre os meses de janeiro e abril de 2005, sendo as informações coletadas na forma de diálogos, com flexibilidade de tópicos anotados em fichas, registradas em gravador e em fotografias. A segunda ocorreu entre os meses de junho e dezembro de 2005 , onde se percorreu todas as comunidades preenchendo o questionário e identificando possíveis problemas nas entrevistas feitas anteriormente.

A fórmula de cálculo da margem de comercialização e do markup foi baseada em Mendes (1998) e Reis; Carvalho (1999). A tabela 1 apresenta a fórmula da margem bruta de comercialização, mensurada pela diferença de preços entre os agentes que participam do processo de comercialização.

Tabela 1. Fórmulas para o cálculo da margem de comercialização.

Table 1. Formulas for calculation the commercialization margin.

\begin{tabular}{lcc}
\hline Margem & Valor absoluto & Valor relativo \\
\hline Total $(\mathrm{Mt})$ & $\mathrm{Pv}-\mathrm{Pp}$ & {$[(\mathrm{Pv}-\mathrm{Pp}) / \mathrm{Pv}] 100$} \\
Intermediário & $\mathrm{Pi}-\mathrm{Pp}$ & {$[(\mathrm{Pi}-\mathrm{Pp}) / \mathrm{Pv}] 100$} \\
Atacado (Ma) & $\mathrm{Pa}-\mathrm{Pp}$ & {$[(\mathrm{Pa}-\mathrm{Pp}) / \mathrm{Pv}] 100$} \\
Varejo $(\mathrm{Mv})$ & $\mathrm{Pv}-\mathrm{Pa}$ & {$[(\mathrm{Pv}-\mathrm{Pa}) / \mathrm{Pv}] 100$} \\
\hline
\end{tabular}

Fonte: Mendes, 1998

Onde:

$\mathrm{Pp}=$ preço em nível de produtor, ou seja, preço de venda ao intermediário;

$\mathrm{Pi}=$ preço em nível de intermediário, ou seja, preço de venda ao atacado;

$\mathrm{Pa}=$ preço em nível de atacadista, ou seja, preço de venda ao varejo;

$\mathrm{Pv}=$ preço em nível de varejo, ou seja, preço pago pelo consumidor.

A tabela 2 apresenta as fórmulas para cálculo do markup de comercialização.

Tabela 2. Fórmulas para o cálculo do markup de comercialização.

Table 2. Formulas for calculation the commercialization markup.

\begin{tabular}{lcc}
\hline Margem & Valor absoluto & Valor relativo \\
\hline Total $(\mathrm{Mt})$ & $\mathrm{Pv}-\mathrm{Pp}$ & {$[(\mathrm{Pv}-\mathrm{Pp}) / \mathrm{Pp}] 100$} \\
Intermediário & $\mathrm{Pi}-\mathrm{Pp}$ & {$[(\mathrm{Pi}-\mathrm{Pp}) / \mathrm{Pp}] 100$} \\
Atacado $(\mathrm{Ma})$ & $\mathrm{Pa}-\mathrm{Pi}$ & {$[(\mathrm{Pa}-\mathrm{Pi}) / \mathrm{Pi}] 100$} \\
Varejo $(\mathrm{Mv})$ & $\mathrm{Pv}-\mathrm{Pa}$ & {$[(\mathrm{Pv}-\mathrm{Pa}) / \mathrm{Pa}] 100$} \\
\hline Fonte: Mendes, 1998 & &
\end{tabular}

Onde:

$\mathrm{Pp}=$ preço em nível de produtor, ou seja, preço de venda ao intermediário;

$\mathrm{Pi}=$ preço em nível de intermediário, ou seja, preço de venda ao atacado;

$\mathrm{Pa}=$ preço em nível de atacadista, ou seja, preço de venda ao varejo;

$\mathrm{Pv}=$ preço em nível de varejo, ou seja, preço pago pelo consumidor. 
Para a análise proposta houve a necessidade da obtenção de coeficientes de conversão de matériaprima para a produção dos diferentes tipos de produto artesanal (cestos), sendo estabelecidos os seguintes:

- Bandeja redonda $\mathrm{n}^{\circ}$ 3: $64 \mathrm{~kg}$ de cipó para a produção de 850 unidades;

- Bandeja retangular $n^{\circ}$ 3: $120 \mathrm{Kg}$ de cipó para a produção de 800 unidades;

- Coração n ${ }^{\circ}$ 2: $66 \mathrm{~kg}$ de cipó para a produção de 1.100 unidades;

- Coração $\mathrm{n}^{\mathrm{o}} 3:$ : 82,5 kg de cipó para produção de 1.100 unidades.

\section{RESULTADOS E DISCUSSÕES}

\section{Cadeia produtiva do cipó-preto}

A figura 1 apresenta o fluxograma da cadeia produtiva do cipó-preto, contendo os diferentes agentes que a compõem, desde sua extração até a utilização final, na forma de artesanato (cestos).

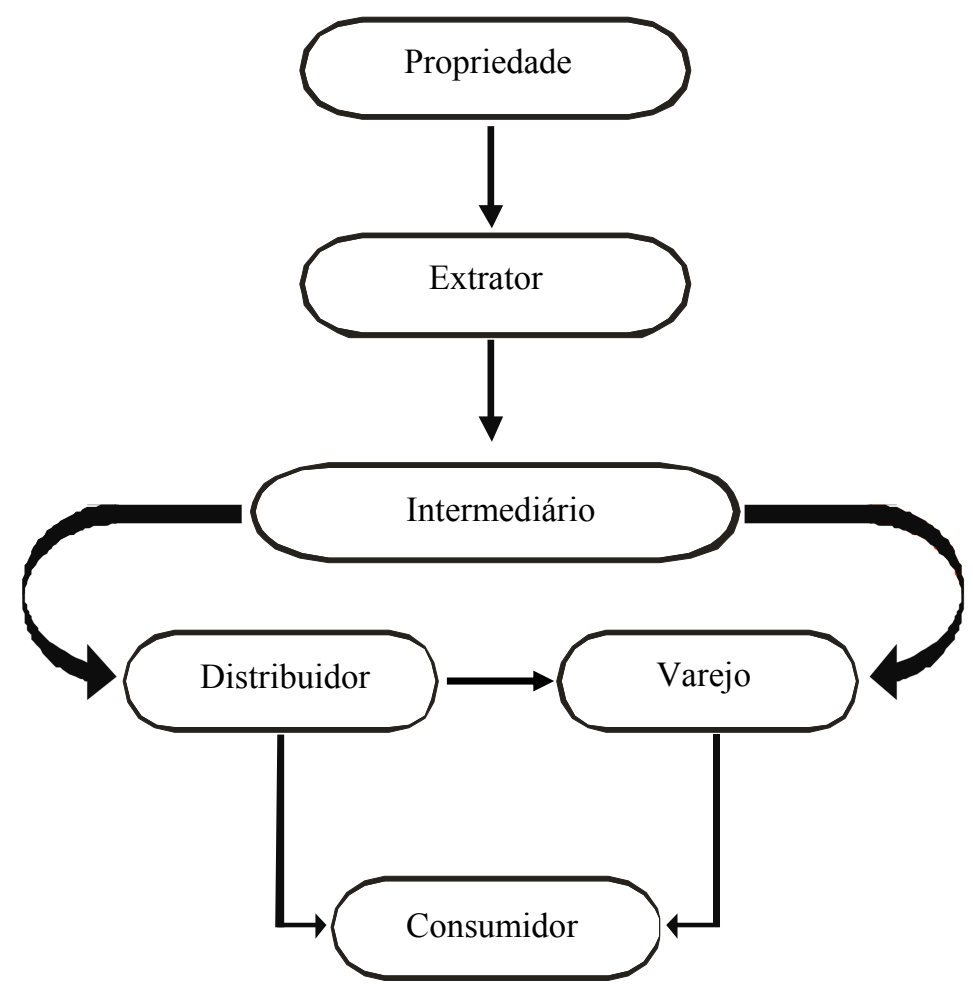

Fonte: Pesquisa de campo, 2005

Figura 1. Fluxograma da cadeia produtiva do cipó-preto na região da APA de Guaratuba, PR.

Figure 1. Cipó-preto productive chain flowchart at the AEP in Guaratuba, PR.

\section{Processo de extração, beneficiamento e comercialização}

$\mathrm{O}$ processo de extração inicia-se no ambiente florestal ou em árvores isoladas em áreas de pastagens. O proprietário da terra, a qual geralmente é coberta por vegetação de porte arbóreo e/ou pastagens, na maioria das vezes, não tem interesse na exploração econômica do cipó-preto e cede ao extrator este direito, com o único objetivo de realizar a limpeza da área, não cobrando nenhum valor pelo cipó extraído. Assim, esse extrator representa o primeiro agente desta cadeia produtiva.

Os extratores, em sua maioria, são jovens do sexo masculino, que saem à procura de árvores onde ocorre o cipó-preto. Cada extrator consegue extrair aproximadamente $30 \mathrm{~kg}$ de cipó diariamente, o qual é transportado em feixes individuais de $15 \mathrm{~kg}$.

De posse do cipó, o objetivo principal das famílias residentes na unidade de Guaratuba, ou seja, nas comunidades mais integradas ao mercado, é utilizá-lo para a confecção de cestarias (artesanatos) feito 
em suas próprias residências e continuando uma tradição de décadas. Para produzir os cestos é necessário fazer o beneficiamento do cipó, que consiste na retirada do córtex, ou seja, na separação da casca da raiz, na secagem e no desfibramento, utilizando-se para tanto, canivetes, estiletes ou um equipamento rústico conhecido como ralador. Para cada quilo de cipó beneficiado, são necessários 10 quilos de cipó bruto. Já as famílias residentes nas comunidades menos integradas ao mercado extraem o cipó e o vende na forma bruta (sem beneficiamento), ou seja, com casca e sem a secagem, em feixes de aproximadamente 30 quilos. Nessas comunidades, as famílias não tecem cestos porque não há mercado, uma vez que o comprador (intermediário) não vai buscá-los devido principalmente à dificuldade de acesso. Portanto, estas famílias vendem o cipó na forma bruta para as famílias residentes em Garuva (SC), já que a distância para este município é menor que para Guaratuba.

\section{Intermediário do artesanato}

Na região da APA foi identificado apenas um único intermediário, residente no estado de São Paulo e que opera na comercialização do artesanato de cipó-preto. Este intermediário faz acordo verbal com os extratores/artesãos para a aquisição de toda a produção mensal do artesanato.

O custo de transporte da região da APA até São Paulo é de difícil mensuração, pois este intermediário não trabalha apenas com cestos, uma vez que no mesmo frete são adquiridos e transportados outros produtos, como cestarias de vime e vasos de diversas formas. Os cestos adquiridos na região são comercializados com distribuidores, varejistas ou diretamente com o consumidor final no estado de São Paulo.

A quantidade de cestos produzida por estas famílias é estimada em função da demanda do intermediário. Este informa às famílias quantos cestos precisa no mês e, através da seção do "fundo", controla o tipo de cesto e a quantidade produzida. É possível a colocação de "fundos" não cedidos pelo intermediário, mas isso levaria ao cancelamento do acordo. Devido à distância dos centros consumidores, a falta de recursos financeiros para a locomoção, conhecimento de mercado etc, as famílias evitam perder o acordo feito com o único intermediário, pois contam com essa renda todos os meses.

A literatura econômica denomina esta estrutura de mercado de monopsônio devido haver um único comprador para vários produtores. Assim, o intermediário determina a quantidade, o tipo e o preço pago pelo artesanato.

\section{Distribuidor}

Agente pouco conhecido nesta cadeia produtiva, opera geralmente nas grandes cidades, principalmente em São Paulo e Belo Horizonte, tendo como seu fornecedor o intermediário descrito anteriormente. $\mathrm{O}$ distribuidor comercializa o produto no varejo ou diretamente ao consumidor final.

O custo de transporte nessa etapa é pago pelo distribuidor, e também é de difícil mensuração, pois o mesmo não trabalha apenas com o artesanato. Geralmente, no mesmo frete ele transporta outros produtos como, por exemplo, guaricana, musgo, banana e farinha de mandioca.

\section{Varejo}

O comércio varejista do artesanato é composto por lojistas do ramo de floricultura, viveiros de plantas ornamentais e supermercados, dentre outros. Entre seus fornecedores estão o intermediário e o distribuidor em grande parte localizados nas cidades de São Paulo e Belo Horizonte. O produto nessa etapa é vendido na mesma forma inicial que saiu da APA, porém os lojistas costumam agregar detalhes às peças para caracterizá-las como utensílios de cozinha e embalagens para jóias e perfumes.

\section{Intermediário da cadeia do cipó-preto sem beneficiamento}

De posse do cipó-preto, as famílias residentes nas comunidades rurais menos integradas ao mercado da APA de Guaratuba, têm como objetivo principal vendê-los sem beneficiamento. Os intermediários são algumas famílias residentes geralmente na cidade de Garuva (SC), e tem como fornecedores as famílias extrativistas residentes nas "comunidades rurais menos integradas ao mercado". Todos os meses se deslocam até as comunidades dos extratores para adquirir a produção do cipó-preto. Estes intermediários são artesãos em suas cidades de origem e realizam o beneficiamento e a confecção

${ }^{1}$ Base de madeira para a confecção do artesanato. 
dos cestos. A produção é vendida no comércio varejista da região ou diretamente ao consumidor final. Estes intermediários são responsáveis pelo frete, porém aproveitam-no para transportar o cipó junto a outras mercadorias. Geralmente são estes mesmos intermediários que adquirem a produção de outros Produtos Florestais Não Madeiráveis da região, como folhas de guaricana, de samambaia e o musgo. Nessa atividade a estrutura de mercado é o oligopólio, já que existem poucos compradores para muitos vendedores.

\section{Análise da produção de artesanato}

Produção, preço de venda e receita bruta

Observa-se que nas regiões mais integradas ao mercado da APA de Guaratuba existem 55 famílias que utilizam o cipó-preto para tecer artesanato. A renda gerada por essa atividade situa-se abaixo do salário mínimo vigente no país (Tabela 3). A produção é representada por quatro tipos de cestos, sendo: bandeja redonda $n^{\circ} 3$; bandeja retangular $n^{\circ} 3$; coração $n^{\circ} 2$ e coração $n^{\circ} 3$. Juntas estas famílias produzem 53 mil unidades por mês, vendidas em média por R\$ 0,21/unidade (vinte e um centavos). A venda destes cestos gera uma renda bruta de R\$ 11.066,00 (onze mil e sessenta e seis reais), o que representa em média R \$ 201,20 (duzentos e um reais e vinte centavos) mensais por família.

A bandeja retangular $\mathrm{n}^{\circ} 3$ é produzida por $27,3 \%$ das famílias pesquisadas e, apesar ter a menor produção por unidade, é a que gera maior renda, pois é o produto com maior valor unitário R\$ 0,24 (vinte e quatro centavos). Já a bandeja redonda $n^{\circ} 3$, que gera a menor renda bruta entre as famílias, apresenta produção unitária 5,8\% superior à retangular $\mathrm{n}^{\circ} 3$, mesmo com o valor de venda $16,7 \%$ inferior $(\mathrm{R} \$$ 0,20/unidade).

O coração $n^{\circ} 3$ é produzido por $32,7 \%$ das famílias pesquisadas, o maior número de famílias, porém a produção unitária é a mesma do coração $n^{\circ} 2$, mas a renda gerada é $5,9 \%$ superior, pois cada unidade do coração $n^{0} 3$ é vendido a $\mathrm{R} \$ 0,17$ (dezessete centavos), cerca de $6 \%$ superior ao coração $n^{\circ} 2$ que é de R\$ 0,16/unidade (Tabela 3).

Tabela 3. Número de famílias, produção familiar, preço de venda e receita bruta total do artesanato por mês.

Table 3. Number of families, family business production, market price and gross income from the craft industry by month.

\begin{tabular}{|c|c|c|c|c|c|c|}
\hline \multirow{2}{*}{$\begin{array}{l}\text { Produto } \\
\text { Artesanato }\end{array}$} & \multicolumn{2}{|c|}{$\mathrm{N}^{0}$ de famílias } & \multicolumn{2}{|c|}{$\begin{array}{c}\text { Produção das famílias } \\
\text { (unidades/mês) }\end{array}$} & \multirow{2}{*}{$\begin{array}{l}\text { Preço de venda } \\
\text { (R\$/mês) } \\
\text { Unitário }\end{array}$} & \multirow{2}{*}{$\begin{array}{c}\text { Receita bruta } \\
\text { (R\$/mês/total) } \\
\text { Total }\end{array}$} \\
\hline & Absoluto & $(\%)$ & Absoluto & $(\%)$ & & \\
\hline Bandeja redonda $n^{\circ} 3$ & 12 & 21,8 & 850 & 22,1 & 0,20 & 170,00 \\
\hline Bandeja retangular $n^{\circ} 3$ & 15 & 27,3 & 800 & 20,8 & 0,24 & 192,00 \\
\hline Coração $n^{\circ} 2$ & 10 & 18,2 & 1.100 & 28,6 & 0,16 & 176,00 \\
\hline Coração $n^{\circ} 3$ & 18 & 32,7 & 1.100 & 28,6 & 0,17 & 187,00 \\
\hline Total geral & 55 & 100,0 & 53.000 & 100,0 & 0,21 & $11.066,00$ \\
\hline
\end{tabular}

Fonte: Pesquisa de campo, 2005.

O custo total da fabricação de 53 mil unidades do artesanato é de R\$ 10.422,00 (dez mil quatrocentos e vinte e dois reais), média de $\mathrm{R} \$ 189,50$ (cento e oitenta e nove reais e cinqüenta centavos) por família. São 155,8 dias na capina a um custo de $\mathrm{R} \$ 2.337,00$ (dois mil trezentos e trinta e sete reais), 222 dias no beneficiamento a um custo de R\$ 3.330,00 (três mil trezentos e trinta reais) e 317 dias na confecção dos cestos artesanais a um custo de $\mathrm{R} \$ 4.755,00$ (quatro mil setecentos e cinqüenta e cinco reais) (Tabela 4).

Esses custos referem-se apenas à mão-de-obra de uma pessoa adulta trabalhando 8 horas por dia no valor médio regional de $\mathrm{R} \$ 15,00$ (quinze reais). A diferença de valores entre os custos nas diversas etapas da produção ocorre, porque é diferente a quantidade de dias/homens e de matéria-prima necessários para produzir os quatros produtos. A bandeja retangular $\mathrm{n}^{\circ} 3$ tem o maior custo, 30,6\% superior à bandeja redonda $\mathrm{n}^{\circ} 3$ e o coração $\mathrm{n}^{\circ} 3$, é $11,7 \%$ mais caro de produzir do que o coração $\mathrm{n}^{\circ} 2$. Isso explica a diferença no valor de vendas entre os quatro diferentes produtos (Tabela 4).

\section{Custo, receita líquida e margem de lucro}

As margens de lucros são geralmente baixas, sendo que em alguns casos se verifica prejuízo 
econômico. Embora as análises revelem tal situação, faz-se necessário pontuar que as receitas advindas da comercialização dos cestos representam a remuneração da mão-de-obra. Neste contexto, a receita bruta da comercialização do artesanato representa a renda mensal disponível (Tabela 5). Nesta linha de raciocínio, observa-se que a bandeja redonda $\mathrm{n}^{\circ} 3$ apresenta uma margem de lucro de $11,8 \%$, superior em relação à bandeja retangular $n^{\circ} 3(12,3 \%)$, mas a receita bruta advinda com a venda da bandeja retangular $n^{\circ} 3$ é superior à bandeja redonda $\mathrm{n}^{\mathrm{0}} 3$. Isso ocorre também com o coração $\mathrm{n}^{\mathrm{0}} 3$ cuja margem de lucro é 5,9\%, contra $0,3 \%$ do coração $n^{\circ} 2$.

Tabela 4. Número de dias, custo das etapas do processo de produção e custo do artesanato por família por mês.

Table 4. Number of days, production costs by stage, and craft costs per family by month.

\begin{tabular}{|c|c|c|c|c|c|c|c|}
\hline \multirow{2}{*}{$\begin{array}{l}\text { Produto } \\
\text { Artesanato }\end{array}$} & \multicolumn{2}{|c|}{$\begin{array}{l}\text { Custo de extração } \\
\text { do cipó/mês }\end{array}$} & \multicolumn{2}{|c|}{$\begin{array}{c}\text { Custo do } \\
\text { beneficiamento/mês }\end{array}$} & \multicolumn{2}{|c|}{$\begin{array}{l}\text { Custo da produção } \\
\text { de artesanato/mês }\end{array}$} & \multirow{2}{*}{$\begin{array}{l}\text { Custo total por } \\
\text { família/mês } \\
\text { (R\$) }\end{array}$} \\
\hline & (Dias) & (R\$) & (Dias) & (R\$) & (Dias) & (R\$) & \\
\hline Bandeja redonda $\mathrm{n}^{\circ} 3$ & 2,1 & 31,50 & 3 & 45,00 & 5 & 75,00 & 151,50 \\
\hline Bandeja retangular $n^{\circ} 3$ & 4 & 60,00 & 5,6 & 84,00 & 5 & 75,00 & 219,00 \\
\hline Coração $n^{\circ} 2$ & 2,2 & 33,00 & 3 & 45,00 & 6,5 & 97,50 & 175,50 \\
\hline Coração n 3 & 2,7 & 40,50 & 4 & 60,00 & 6,5 & 97,50 & 198,00 \\
\hline Total geral & 155,8 & $2.337,00$ & 222 & $3.330,00$ & 317 & $4.755,00$ & $10.422,00$ \\
\hline
\end{tabular}

Fonte: Pesquisa de campo, 2005.

O custo de produção da bandeja retangular $n^{\circ} 3$ é $44 \%$ maior que o da bandeja redonda $n^{\circ} 3$, porém a receita bruta é apenas $11 \%$ superior. $\mathrm{O}$ custo de produção do coração $\mathrm{n}^{0} 3$ é $23,5 \%$ superior ao do coração $n^{\circ} 2$, enquanto a receita bruta é superior, apenas em $6,25 \%$. Isso explica a diferença na receita liquida e na margem de lucro (Tabela 5).

Tabela 5. Custo de produção, receita bruta, receita líquida e margem de lucro do artesanato mensal por família.

Table 5. Production costs, gross income, net income, and profit margin per family by month.

\begin{tabular}{|c|c|c|c|c|}
\hline $\begin{array}{l}\text { Produto } \\
\text { Artesanato }\end{array}$ & $\begin{array}{c}\text { Custo familiar de } \\
\text { produção/mês } \\
\text { (R\$) }\end{array}$ & $\begin{array}{c}\text { Receita bruta } \\
\text { familiar/mês } \\
\text { (R\$) }\end{array}$ & $\begin{array}{c}\text { Receita líquida } \\
\text { familiar/mês } \\
\text { (R\$) }\end{array}$ & $\begin{array}{c}\text { Margem de lucro } \\
\text { (\%) }\end{array}$ \\
\hline Bandeja redonda $\mathrm{n}^{\circ} 3$ & 152,00 & 170,00 & 18,00 & 11,8 \\
\hline Bandeja retangular $n^{\circ} 3$ & 219,00 & 192,00 & $(27,00)$ & $(12,3)$ \\
\hline Coração $n^{\circ} 2$ & 175,50 & 176,00 & 0,50 & 0,3 \\
\hline Coração $n^{\circ} 3$ & 198,75 & 187,00 & $(11,75)$ & $(5,9)$ \\
\hline Total Geral & 186,31 & 181,25 & $(5,06)$ & $(6,1)$ \\
\hline
\end{tabular}

Fonte: Pesquisa de campo, 2005.

\section{Análise da comercialização de cipó-preto sem beneficiamento}

Quantidade extraída, preço de venda e receita bruta

As informações apresentadas na tabela 6 evidenciam que todas as famílias extrativistas entrevistadas na unidade de Guaratuba, nas comunidades rurais "menos integradas ao mercado", são extratoras do cipó-preto. Cada família extrai em média $180 \mathrm{~kg}$ de cipó por mês e comercializa ao preço de $\mathrm{R} \$ 0,60$ o quilo, totalizando receita bruta média de $\mathrm{R} \$ 108,00$, inferior a 50\% do salário mínimo vigente.

Tabela 6. Número de famílias, quantidade extraída por família, preço de venda e receita bruta mensal do cipó-preto sem beneficiamento nas comunidades menos integradas ao mercado.

Table 6. Number of families, harvested amount per family, market price, and monthly gross income of non-manufactured cipó-preto.

\begin{tabular}{lccccc}
\hline PFNMS & $\begin{array}{c}\text { Número de } \\
\text { famílias } \\
\text { Absoluto }\end{array}$ & $\begin{array}{c}\text { Quantidade extraída } \\
\text { por família/mês } \\
(\mathbf{( k g )}\end{array}$ & $\begin{array}{c}\text { Preço de venda por kg } \\
(\mathbf{R S )}\end{array}$ & $\begin{array}{c}\text { Renda bruta } \\
\text { familiar/mês } \\
(\mathbf{R})\end{array}$ \\
\hline Cipó-preto & 18 & 100 & 180 & 0,60 & 108,00 \\
\hline Fonte: Pesquisa de campo, 2005. & & & &
\end{tabular}




\section{Custo, receita líquida e margem de lucro}

Verifica-se na tabela 7 que as famílias utilizam apenas seis dias por mês no trabalho de extração do cipó-preto. O custo de extração de $180 \mathrm{~kg}$ de cipó-preto por família é de $\mathrm{R} \$ 90,00$, baseada na remuneração da diária de $\mathrm{R} \$ 15,00$, vigente na região.

Cada família extrai em média $30 \mathrm{~kg}$ de cipó por dia e o vende na forma bruta por $\mathrm{R} \$ 0,60 / \mathrm{kg}$, obtendo uma receita bruta mensal de $\mathrm{R} \$ 108,00$. Desta forma, o lucro líquido é de $\mathrm{R} \$ 18,00$ por família, o que significa uma margem de lucro de $16,7 \%$, porém as famílias consideram a receita bruta como renda líquida disponível, pois os custos referem-se à mão-de-obra familiar empregada na atividade.

Tabela 7. Número de dias, custo de extração, receita bruta, receita líquida e margem de lucro da extração do cipó-preto sem beneficiamento, por família/mês.

Table 7. Number of days, harvest costs, gross income, net income, and non-manufactured cipó-preto profit margin per family/month.

\begin{tabular}{lccccc}
\hline PFNMS & $\begin{array}{c}\text { Número de dias } \\
\text { de extração }\end{array}$ & $\begin{array}{c}\text { Custo da } \\
\text { extração/mês } \\
(\mathbf{R} \mathbf{)}\end{array}$ & $\begin{array}{c}\text { Receita bruta } \\
\text { familiar/mês } \\
(\mathbf{R} \mathbf{)}\end{array}$ & $\begin{array}{c}\text { Receita líquida } \\
\text { familiar/mês } \\
(\mathbf{R} \mathbf{)})\end{array}$ & $\begin{array}{c}\text { Margem de lucro } \\
(\%)\end{array}$ \\
\hline Cipó-preto & 6 & 90,00 & 108,00 & 18,00 & 16,7 \\
\hline Fonte: Pesquisa de campo, 2005. & & &
\end{tabular}

\section{Margem de comercialização na cadeia produtiva do cipó-preto}

As informações contidas na tabela 8 evidenciam que, para os diferentes tipos de artesanato, existe um aumento nos percentuais de margem de comercialização, do produtor até o consumidor final, mostrando que os maiores ganhos se verificam ao nível de distribuidor (atacado) ou varejo.

No caso da Bandeja redonda $\mathrm{n}^{\mathrm{o}} 3$ o agente distribuidor se apropria da maior fatia dos ganhos em relação ao preço pago pelo consumidor $(37,9 \%)$. O mesmo se repete para a Bandeja retangular $\mathrm{n}^{\mathrm{o}} 3$, onde também o distribuidor se apropria da maior fatia da margem de comercialização (39,4\%).

Para os artesanatos tipo Coração $\mathrm{n}^{\circ} 2$ e Coração $\mathrm{n}^{\circ} 3$, o comércio varejista é o que realiza a maior apropriação dos ganhos dentro do sistema de comercialização, ou seja, 38,9\% e 42,8\% respectivamente (Tabela 8).

Em relação à margem total de comercialização, que indica a relação entre o preço pago pelo consumidor e o preço pago ao produtor, o artesanato tipo Bandeja redonda $\mathrm{n}^{\mathrm{o}} 3$ detém a maior margem total de comercialização, de 93,1\% mensais, porém os ganhos expressivos dessa atividade concentram-se a partir do intermediário, levando à constatação que o valor pago ao extrator é baixo, mantendo a dependência e a exclusão social (Tabela 8).

Tabela 8. Preço de venda e margem de comercialização entre os diferentes agentes da cadeia produtiva do cipó-preto.

Table 8. Market price and market margin for the different agents of cipó-preto craft productive chain.

\begin{tabular}{lccccc}
\hline \multirow{2}{*}{ Artesanato } & \multicolumn{3}{c}{ Preços de venda em Reais e margem de comercialização em \% } & Margem total \\
\cline { 2 - 5 } & Extrator & Intermediário & Distribuidor & Varejo & \% \\
\hline Preço da Bandeja redonda ${ }^{\circ}$ 03 & 0,20 & 0,90 & 2,00 & 2,90 & \\
Margem em \% & 0,0 & 24,1 & 37,9 & 31,0 & 93,1 \\
Preço da Bandeja retangular 03 & 0,24 & 1,20 & 2,50 & 3,30 & \\
Margem em \% & 0,0 & 29,1 & 39,4 & 24,2 & 92,7 \\
Preço do Coração n ${ }^{\circ} 02$ & 0,16 & 0,50 & 1,10 & 1,80 & \\
Margem em \% & 0,0 & 18,9 & 33,3 & 38,9 & 91,1 \\
Preço do Coração n ${ }^{\circ} 03$ & 0,17 & 0,60 & 1,20 & 2,10 & \\
Margem em \% & 0,0 & 20,5 & 28,6 & 42,8 & 91,9 \\
\hline
\end{tabular}

Fonte: Pesquisa de campo, 2005.

\section{Markup de comercialização na cadeia produtiva do cipó-preto}

Os intermediários representam os agentes da cadeia produtiva que obtém os maiores markup de comercialização, seguidos pelos distribuidores e pelo comércio varejista. Os percentuais de markup de comercialização são diferenciados para cada tipo de produto (Tabela 9).

A bandeja redonda $n^{\circ} 3$ é vendida ao intermediário pelo extrator/artesão por $\mathrm{R} \$ 0,20$ a unidade. 
Este intermediário revende este mesmo produto ao distribuidor ou ao comércio varejista por R $\$ 0,90$, obtendo um markup de comercialização de 350\%. O distribuidor, por sua vez, revende este mesmo produto ao comércio varejista ou ao consumidor final por $\mathrm{R} \$ 2,00$ a unidade, obtendo um markup de $122,2 \%$. Finalizando a cadeia de comercialização, o comércio varejista comercializa o produto para o consumidor por $\mathrm{R} \$ 2,90$, obtendo um markup de 45\%. O markup total de comercialização entre o extrator/artesão e o consumidor final atinge $1.350 \%$ (Tabela 9).

A bandeja retangular $n^{\circ} 3$ é comercializada pelo extrator/artesão ao intermediário por R\$ 0,24 a unidade. Este intermediário revende o mesmo produto ao distribuidor ou ao comércio varejista por R\$ 1,20 , obtendo um markup de 400,0\%. O distribuidor, por sua vez, comercializa este produto com o comércio varejista ou com o consumidor final por $\mathrm{R} \$ 2,50$, obtendo um markup de $108,3 \%$. O comércio varejista revende o produto ao consumidor final por $\mathrm{R} \$ 3,30$, obtendo markup de $32 \%$. O markup total de comercialização entre o extrator/artesão e o consumidor final atinge 1.275\% (Tabela 9).

Tabela 9. Preço de venda e markup de comercialização entre os diferentes agentes da cadeia produtiva do artesanato nas comunidades rurais mais integradas ao mercado.

Table 9. Market price and mark-up for the different agents of craft productive chain.

\begin{tabular}{|c|c|c|c|c|c|}
\hline \multirow{2}{*}{ Artesanato } & \multicolumn{4}{|c|}{ Preços de venda em reais e markup de comercialização em \% } & \multirow{2}{*}{$\begin{array}{c}\text { Markup total } \\
\%\end{array}$} \\
\hline & Extrator & Intermediário & Distribuidor & Varejo & \\
\hline Bandeja redonda $\mathrm{n}^{\circ} 03$ & 0,20 & 0,90 & 2,00 & 2,90 & \\
\hline Markup em \% & 0,0 & 350 & 122,2 & 45 & 1350 \\
\hline Bandeja retangular 03 & 0,24 & 1,20 & 2,50 & 3,30 & \\
\hline Markup em \% & 0,0 & 400,0 & 108,3 & 32 & 1275 \\
\hline Coração nº2 & 0,16 & 0,50 & 1,10 & 1,80 & \\
\hline Markup em \% & 0,0 & 212,5 & 120 & 63,6 & 1025 \\
\hline Coração nº3 & 0,17 & 0,60 & 1,20 & 2,10 & \\
\hline Markup em \% & 0,0 & 252,9 & 100 & 75 & $1.135,3$ \\
\hline
\end{tabular}

Fonte: Pesquisa de campo, 2005.

O coração $n^{\circ} 2$ é comercializado pelo extrator/artesão ao intermediário por R $\$ 0,16$. Este revende para o distribuidor ou para o varejo por $\mathrm{R} \$ 0,50$, obtendo markup de comercialização de $212,50 \%$. O distribuidor revende ao varejo ou ao consumidor final por $\mathrm{R} \$ 1,10$, obtendo markup de comercialização de $120 \%$. O varejo vende ao consumidor final por $\mathrm{R} \$ 1,80$, obtendo markup de $63,6 \%$. O markup total de comercialização entre o extrator/artesão e o consumidor final atinge $1.025 \%$

O Coração $n^{\circ} 3$ é comercializado pelo extrator/artesão ao intermediário por R $\$ 0,17$ e deste para o distribuidor por $\mathrm{R} \$ 0,60$, obtendo markup de comercialização de 252,9\%. O distribuidor revende este produto ao comércio varejista ou ao consumidor final por $\mathrm{R} \$ 1,20$, obtendo markup de $100 \%$. O comércio varejista por sua vez comercializa o produto com o consumidor final por R $\$ 2,10$, obtendo um markup de $75 \%$. O markup total de comercialização entre o extrator/artesão e o consumidor final atinge 1135,3\%.

\section{CONCLUSÕES}

As observações realizadas na execução do trabalho possibilitam concluir que a cadeia produtiva do cipó-preto na APA de Guaratuba apresenta-se bastante simplificada, ou seja, existem poucos agentes em função da inexistência de processos mais complexos de beneficiamento, à exceção da confecção do artesanato.

Os custos de produção representam a remuneração da mão-de-obra, não sendo desta forma recomendável a realização de uma análise de rentabilidade tradicional, uma vez que o extrator não possui outra destinação alternativa, exceto a agricultura de subsistência e outros PFNM's.

A análise da margem de lucro evidencia a necessidade da valorização econômica das atividades extrativistas, uma vez que o extrator do cipó-preto é o agente com menor remuneração na cadeia produtiva. produtiva

Os intermediários são os agentes que apresentam maiores margens e markups na cadeia

A pesquisa de campo sinaliza para uma estrutura de mercado monopsônica, uma vez que existe 
um único grande comprador que comercializa os produtos confeccionados pelos artesãos no estado de São Paulo. Este intermediário determina o quantum a ser extraído mensalmente, bem como, os preços de comercialização dos produtos.

Apesar de as famílias extratoras afirmarem que a atividade extrativa do cipó é sustentável, há a necessidade de estudos acerca da sustentabilidade desta atividade, como a determinação do real estoque deste recurso, sua capacidade regenerativa, manejo adequado, assim como a determinação de indicadores ecológicos que envolvem sua extração.

Atendidos os aspectos de sustentabilidade da extração do recurso, da viabilidade econômica e social da atividade, recomenda-se:

- Organizar a produção atual através da criação de organizações associativistas ou cooperativistas com o apoio de universidades e instituições de extensão e assistência técnica.

- Cadastrar as famílias extrativistas pelo órgão de fiscalização competente.

- Elaborar uma normatização provisória sobre a extração e beneficiamento do cipó-preto e dos demais PFNM's.

- Levantamento de outros PFNM's potenciais para o mercado, aliado ao desenvolvimento de tecnologias para agregação de valor.

- Elaborar projetos de marketing no sentido de se buscar novos mercados para o cipó-preto e os demais PFNM's existentes.

\section{REFERÊNCIAS}

BORGES, K. H.; BRAZ, E. M. Recursos Florestais não madeireiros, versão preliminar do Workshop "Manejo de recursos não madeireiros - perspectivas para a Amazônia". Rio Branco, AC, Junho/1998.

HADDAD, P. R. (org). A competitividade do agronegócio e desenvolvimento regional. Estudo de "cluster". Brasília: CNPQ/EMBRAPA, 1999.

ITTO. The Case for Multiple-use Management on Tropical Hardwood Forests. Harvard University Cambridge. Massachusetts. 1988.

LIMA, R. X. Estudos etnobotânicos em comunidades continentais da Área de Proteção Ambiental de Guaraqueçaba - Paraná, Brasil. Curitiba, 1996, 123 p. Dissertação de Mestrado em Ciências Florestais. UFPR.

MAYO, S. J.; BOGNER, J.; BOYCE, P. C.; FRENCH, J. C.; HEGNAUER, R. The Genera of Araceae. Royal Botanical Gardens, Kew, 1997.

MENDES, J. T. Economia agrícola. Ed. Curitiba, PR 1998.

PANAYOTOU, T.; ASHTON, P. Not by timber alone: the case for multiple use management of tropical forests. Island Press, Covelo, CA, 1992.

REIS, A. J. dos; CARVALHO, F. A. de P. Comercialização agrícola no contexto agroindustrial. UFLA/FAEPE. In: Curso de Especialização de Pós-Graduação "Latu Sensu”. Ensino a Distancia. Lavras, 1999.

SANTOS, A. J.; HILDEBRAND, E.; PACHECO, C. H. P.; PIRES, P. T. L.; ROCHADELLI, R. Produtos não madeiráveis: conceituação, classificação, valoração e mercados. Curitiba, 14p. Revista Floresta, 2005.

SONDA, C. Comunidades rurais tradicionais da Área de Proteção Ambiental de Guaratuba: caracterização sócioeconômica e utilização dos recursos vegetais silvestres. 193f. Tese (Doutorado em Ciências Florestais) - Setor de Ciências Agrárias, Universidade Federal do Paraná. Curitiba, 2002. 